\title{
STUDY ON COMPRESSIVE BEARING CAPACITY OF CONCRETE-FILLED SQUARE STEEL TUBE COLUMN REINFORCED BY CIRCULAR STEEL TUBE INSIDE
}

\author{
Yufen $\mathrm{ZHANG}^{\mathrm{a}}$, Junhai ZHAO ${ }^{\mathrm{b}}$, Weifeng $\mathrm{YUAN}^{\mathrm{c}}$ \\ ${ }^{a}$ College of Architecture and Civil Engineering, North China University of Technology, Beijing 100144, China \\ ${ }^{b}$ School of Civil Engineering, Chang' an University, Xi'an 710061, China \\ ${ }^{c}$ School of Civil and Environmental Engineering, Nanyang Technological University, \\ Singapore 639798, Singapore
}

Received 14 Jul 2011; accepted 9 Jan 2012

\begin{abstract}
This paper concentrates on the compressive bearing capacity of one composite column of a Concrete-Filled Square Steel Tube (CFSST) reinforced by a circular steel tube inside. Some tests were conducted to consider the compression behaviour of the stub columns under axial compressive loading. Through an elastoplastic limit analysis based on Unified Strength Theory (UST), the ultimate load capacity of the CFSST columns reinforced by inner circular steel tube under axial compression has been derived, which has a good agreement with the experimental results in comparison with other empirical models. So this model is extended to predict the optimal design of the inner tube, namely, $D_{i} / t_{i}$ and $D_{i} / B$. In addition, another simple model is also proposed to testify the optimal section of this composite column. With the optimal circular steel tubes inside the CFSST column, the composite column can result in significant savings in column size, which ultimately can lead to significant economic savings and higher bearing capacity. The results show that it has a theoretical significance and application value to adopt circular steel tube to strengthen CFSST column.

Keywords: CFSST column; reinforced by circular steel tube inside; compressive bearing capacity; unified strength theory; optimum design.

Reference to this paper should be made as follows: Zhang, Y.; Zhao, J.; Yuan, W. 2013. Study on compressive bearing capacity of concrete-filled square steel tube column reinforced by circular steel tube inside, Journal of Civil Engineering and Management 19(6): 787-795. http://dx.doi.org/10.3846/13923730.2013.799088
\end{abstract}

\section{Introduction}

Concrete-filled steel tube (CFST) has been applied widely in civil engineering for many years. To this date, there have been a number of studies conducted to investigate the behaviour of CFST columns (Ou et al. 2011). The main benefit of using CFST is that it utilises the advantages of both steel and concrete, viz. steel members have high tensile strength and ductility, whereas concrete members are advantageous in compressive strength and stiffness (Varma et al. 2004). Based on the CFST column, this paper introduces one new type of member into the whole CFST family, which is a concrete-filled square steel tube (CFSST) that is reinforced by a circular steel tube inside. Similar to the common CFSTs, this composite column exhibits excellent structural and constructional benefits (Pei 2005). Most important is that this type of column has good fire resistance. When the outer square tube was no longer in force in the blaze, the inner circular tube could confine the concrete to keep the column effective. Jiang et al. (2008) has introduced the concretefilled circular steel tubular column reinforced by circular steel tube inside, and it was concluded that the composite column could improve the compressive capacity as well as the shear capacity and ductility. This column with no more than $600 \mathrm{~mm}$ in diameter has been used in Wuppertal city building in German. It resolved the problem of one fire-resisting and overloading column with the capacity of $8000 \mathrm{kN}$ load. Researches (Roeder et al. 2009, 2010) showed that circular steel tube provided greater bond stress transfer, better confinement and greater shear reinforcement to the in-filled concrete than rectangular steel tube. However, CFSSTs are often used in practice because the design provisions and the structural connections for circular cross-section are not well defined. Therefore, the CFSST column reinforced by inner circular steel tube has important benefits, i.e. it takes the advantage of both the good performance of circular tube to confine 
concrete and the convenient constitution of connection between the CFSST column and the frame beam. Furthermore, this column, without needing to consider the limit of axial compression force ratio, can reduce the column size to provide substantial benefits where floor space is at a premium such as in car parks and office blocks.

To facilitate the practical application of the composites in column seismic retrofit, the ultimate compressive strength of this composite column needs to be well calculated and properly modelled. Several models have been developed, including the superposition method (EN 1994-1-1 2004; Sakino et al. 2004) and the regression analysis based on the tests considering steel ratio and confinement factor (Tan, Zhang 2010; Zhong 2000). In this paper, one new model is proposed for predicting the squash load of the CFSST column reinforced by an inner circular steel tube. Some tests were conducted to research the compressive bearing capacity and compressive behaviour, and the ultimate bearing capacity of the composite column was analysed by Unified Strength Theory (UST). Compared with the experimental results, the applicability of the new model was testified, so it was extended to predict the optimal design of the inner tube, namely, $D_{i} / t_{i}$ and $D_{i} / B$. Considering the confinement of both outer and inner steel tubes acting on the concrete to limit its volume expansion, one simplified model was also derived to predict the optimal diameter of inner circular tube. Within the optimal designs, the theoretical significance and application value can be achieved to use circular steel tube strengthening the CFSST column.

\section{Test program}

Four types of composite columns were tested in contrast with Jiang's experiment on the concrete-filled circular steel tubular column reinforced by a circular steel tube inside, and the specimens before and after being grouted are shown in Figures 1 and 2, respectively. The aspect ratio of all the specimens is 3 . The concrete was cast in the lab, while the steel tubes were provided by the manufacturer. All the specimens were cured under standard conditions in the lab until the concrete design strength was achieved. The compressive strength of the concrete

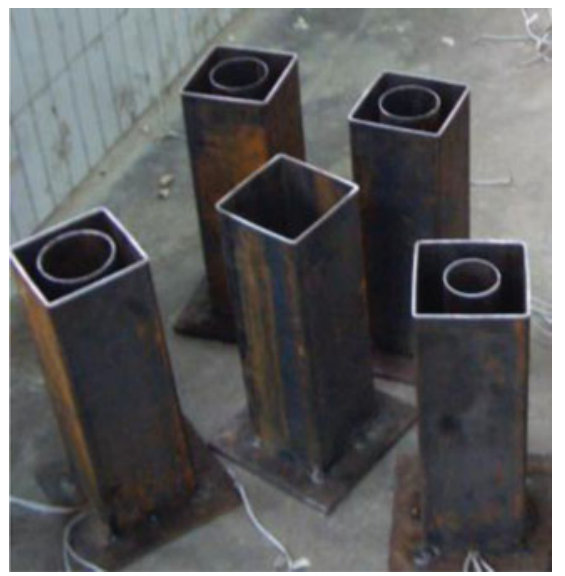

Fig. 1. Specimens before being grouted

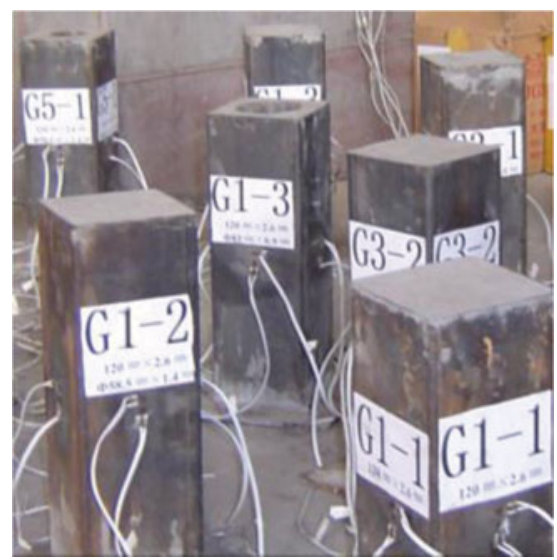

Fig. 2. Specimens after being grouted

was determined using concrete cubes with a side length of $150 \mathrm{~mm}$. It got $f_{\mathrm{c}}=23.6 \mathrm{MPa}$. The other parameters of all specimens are shown in Table 1.

The experiments were conducted under a servo hydraulic machine with a capacity of $5000 \mathrm{kN}$ in static loading. The strain gauges for steel were preset before casting the concrete to measure the vertical and circumferential strain of the tubes. The axial deformation was measured by an electronic extensometer. For acquiring the experimental stress-strain curves of the columns, the specimens were tested to failure under monotonically increasing concentric loads, and the load control mode was $0.15 \mathrm{MPa} / \mathrm{s}$ in stress and then changed to $0.001 \mathrm{MPa} / \mathrm{s}$ in strain after exceeding $80 \%$ of the theoretical peak compressive strength. This maximum load was regarded as the mean ultimate load of each group specimens, listed as $N_{t}$ in the last column of Table 1 .

The typical failure mode of the composite column was local failure mechanism as shown in Figure 3. It can be seen that the outer tube behaves the same way (i.e. forming an outward folding mechanism) as the pure CFSST column. The buckling of the stub column is mainly caused by the expansion of the concrete under axial load. For the specimen G1-4, the transverse strains of inner and outer tubes at the ultimate state were 1500 and $1200 \mu \varepsilon$, respectively. Therefore, both outer square tube and inner circular tube provided some confinement to concrete as it expanded. The outer concrete with the reinforcements of outer square steel tube also surrounds the inner circular steel tube, so the buckling of inner steel tube can be postponed. Meanwhile, the inner concrete is under the circumferential confining force coming from both the inner steel tube and the outer one. With the increase in loading, deformation of the columns increased, and the mutual forces between the steel tubes and concrete became stronger and stronger so as to make the concrete under three-directional compression. The outer steel tube would be yielded first, and next was the inner steel tube. During the ultimate state, concrete was in the plastic state and continually developed micro-cracks inside until the destruction of the specimen. 
Table 1. Experimental parameters

\begin{tabular}{|c|c|c|c|c|c|c|}
\hline Specimen & $\begin{array}{l}\text { Outer tube } \\
B \times t\left(\mathrm{~mm}^{2}\right)\end{array}$ & $\begin{array}{c}f_{s o} \\
(\mathrm{MPa})\end{array}$ & $\begin{array}{c}\text { Inner tube } \\
\Phi D_{i} \times t_{i}\left(\mathrm{~mm}^{2}\right)\end{array}$ & $\begin{array}{c}f_{s i} \\
(\mathrm{MPa})\end{array}$ & $\begin{array}{l}\text { Number of } \\
\text { specimens }\end{array}$ & $\begin{array}{l}\text { Ultimate load } \\
\qquad N_{t}(k N)\end{array}$ \\
\hline G1-1 & $120 \times 2.6$ & 407.5 & - & - & 1 & 896 \\
\hline G1-2 & $120 \times 2.6$ & 407.5 & $\Phi 58.5 \times 1.4$ & 352.5 & 2 & 980 \\
\hline G1-3 & $120 \times 2.6$ & 407.5 & $\Phi 74.0 \times 0.9$ & 680.0 & 3 & 1040 \\
\hline G1-4 & $120 \times 2.6$ & 407.5 & $\Phi 83.0 \times 0.9$ & 597.0 & 2 & 1080 \\
\hline
\end{tabular}

\section{Ultimate bearing capacity of axially loaded short columns}

\subsection{Limit equilibrium method}

The composite column was divided into four parts outer steel tube, inner steel tube, outer concrete and inner concrete in order that every part would be conducted by elastoplastic analysis, respectively. In the state of limit equilibrium, the ultimate axial bearing capacity of the composite column is composed of these four terms. That is:

$$
N=\overline{f_{s o}} A_{s o}+\overline{f_{s i}} A_{s i}+\overline{f_{c o}} A_{c o}+\overline{f_{c i}} A_{c i},
$$

where $f$ is defined as the compressive strength of steel or concrete and $A$ is defined as the area of cross-section. The subscripts $s, c, o$ and $i$ in this paper are the abbreviations for steel, concrete, outer and inner, respectively. And the topmark of '-' means the actual strength when the column is under ultimate state.

\subsection{Unified strength theory}

Under the ultimate state of the composite column, every part can be analysed by UST. The UST (Yu 2004) considers the two larger principal shear stresses and the corresponding normal stresses and their different effects on the failure of materials. When the relationship function

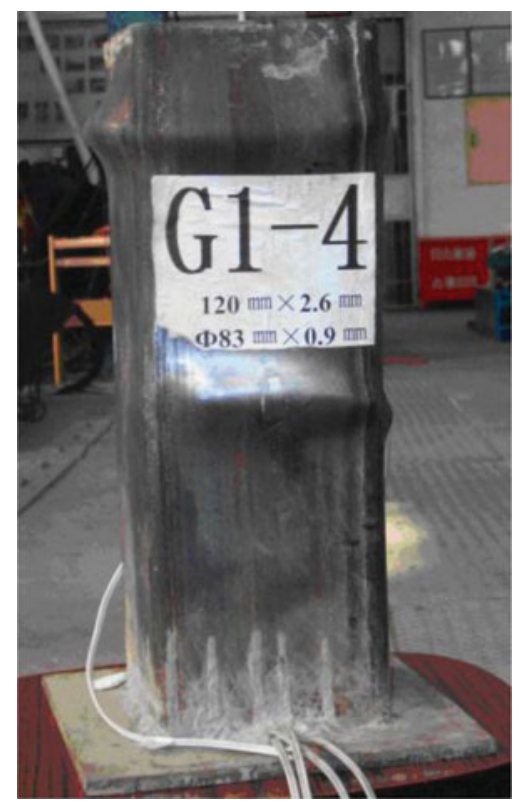

Fig. 3. Typical failure mode of specimen G1-4 between them reaches one ultimate value, the material can be defined as failure at this state which is formulated as follows:

$$
\begin{gathered}
F=\tau_{13}+b \tau_{12}+\beta\left(\sigma_{13}+b \sigma_{12}\right)=C, \\
\text { when } \tau_{12}+\beta \sigma_{12} \geq \tau_{23}+\beta \sigma_{23} \\
F^{\prime}=\tau_{13}+b \tau_{23}+\beta\left(\sigma_{13}+b \sigma_{23}\right)=C, \\
\text { when } \tau_{12}+\beta \sigma_{12} \leq \tau_{23}+\beta \sigma_{23}
\end{gathered}
$$

where: $\tau_{12}, \tau_{23}$ and $\tau_{13}$ are the principal shear stresses, $\tau_{13}=$ $\left(\sigma_{1}-\sigma_{3}\right) / 2, \tau_{12}=\left(\sigma_{1}-\sigma_{2}\right) / 2$ and $\tau_{23}=\left(\sigma_{2}-\sigma_{3}\right) / 2 ; \sigma_{12}$, $\sigma_{23}$ and $\sigma_{13}$ are the corresponding normal stresses on the principal shear stress element; $\sigma_{1}, \sigma_{2}$ and $\sigma_{3}$ are the principal stresses, $\sigma_{1} \geq \sigma_{2} \geq \sigma_{3} . b$ is a weighting coefficient, reflecting the relative effect of the intermediate principal shear stress $\tau_{12}$ or $\tau_{23}$ on the strength of materials; $C$ equals to the material strength. Denoting the tension-compression strength ratio as $\alpha=\sigma_{t} / \sigma_{c}$, we rewrite Eqns (2a) and (2b) in terms of principal stresses as follows:

$$
\begin{gathered}
F=\sigma_{1}-\frac{\alpha}{1+b}\left(b \sigma_{2}+\sigma_{3}\right)=\sigma_{t}, \\
\text { when } \sigma_{2} \leq \frac{\sigma_{1}+\alpha \sigma_{3}}{1+\alpha} ; \\
F^{\prime}=\frac{1}{1+b}\left(\sigma_{1}+b \sigma_{2}\right)-\alpha \sigma_{3}=\sigma_{t}, \\
\text { when } \sigma_{2} \geq \frac{\sigma_{1}+\alpha \sigma_{3}}{1+\alpha} .
\end{gathered}
$$

\subsection{Elastoplastic limit analysis of the composite column}

Because confining mechanism of CFSST is very complex, the square tube can be equivalent to a circular steel tube in the calculation, and two parameters about confinement reduction factor $\zeta$ and concrete strength reduction factor $\gamma_{\mu}$ are considered to compensate this transition.

By the equal-area criterion, the cross-section of square steel tube can be transformed into circular steel tube. The equations are shown as follows:

$$
\begin{aligned}
D_{o}= & 2 B / \sqrt{\pi}=1.1284 B, t_{o}=r_{o}-\left(B-2 t_{s}\right) / \sqrt{\pi}= \\
& r_{o}-0.5642\left(B-2 t_{s}\right),
\end{aligned}
$$

where: $B, t_{s}$ are the side length and thickness of the square steel tube, respectively, and $D_{o}, t_{o}$ are diameter and thickness of equivalent outer steel tube, respectively. Therefore, simplified model of stress of the composite column is shown in Figure 4 ( $p$ means the confining 
pressure). It can be seen that outer concrete gets the confinement only from outer tube, while inner concrete does get from both the tubes.

The inner concrete was filled in a circular tube, and its stresses can be explicated by $0>\sigma_{1}=\sigma_{2}>\sigma_{3}$, $\sigma_{1}=\sigma_{2}=p_{i}+p_{o}^{\prime}$. For $\sigma_{2} \geq \frac{\sigma_{1}+\alpha \sigma_{3}}{1+\alpha}$, substitute them into the stress expression of UST, and the following expression can be obtained:

$$
\sigma_{3}=f_{c}+k_{c}\left(p_{i}+p_{o}^{\prime}\right),
$$

where: $f_{c}$ is the standard strength of concrete; $k_{c}$ is the strength improvement coefficient of concrete under fixed lateral compressive force, and has been studied much. In UST, $k_{c}$ can be calculated by cohesion and friction angle at material failure state. According to the test of Richart et al. (1928), $k_{c}$ has been taken as the constant 4.1 here.

The outer concrete can be expressed as a thickwalled cylinder with an inner diameter $D_{i}$ and an outer diameter $D_{o}$ is subjected to an internal pressure $p_{o}^{\prime}$ and an exterior pressure $p_{o}$. The elastic stress distribution (Lame's Equations) has the form of:

$$
\begin{gathered}
\sigma_{1}=\frac{D_{i}^{2}}{D_{o}^{2}-D_{i}^{2}}\left(1+\frac{D_{o}^{2}}{4 r^{2}}\right) p_{o}^{\prime}-\frac{D_{o}^{2}}{D_{o}^{2}-D_{i}^{2}}\left(1+\frac{D_{i}^{2}}{4 r^{2}}\right) p_{o} \\
\sigma_{2}=\frac{D_{i}^{2}}{D_{o}^{2}-D_{i}^{2}}\left(1-\frac{D_{o}^{2}}{4 r^{2}}\right) p_{o}^{\prime}-\frac{D_{o}^{2}}{D_{o}^{2}-D_{i}^{2}}\left(1-\frac{D_{i}^{2}}{4 r^{2}}\right) p_{o} .
\end{gathered}
$$

The relationship between $p_{o}^{\prime}$ and $p_{o}$ was deduced as $p_{o}^{\prime}=p_{o} \frac{D_{o}}{D_{i}}$, and the Eqns (6a) and (6b) can be changed as $\sigma_{1}=\sigma_{2}=p_{o}$, when $p_{o}^{\prime}=p_{o}$. Because $p_{o}^{\prime}$ is larger than $p_{o}$, the assumption is reasonable and safe for application. Therefore, the ultimate strength of outer concrete can be expressed by:

$$
\sigma_{3}=f_{c}+k_{c} p_{o} .
$$

Therefore, the ultimate strength of concrete has the same expression (Eqn 5). The difference is the value of confining pressure, showing that outer concrete gets the confinement from outer steel tube while inner concrete gets the confinement from both inner and outer steel tube.

The confinement of square steel tubes to concrete is very uneven along the sides (Han, Yang 2003), strong at the four corners and weak along the middle edges. Therefore, the confinement reduction factor $\zeta$ should be considered to reduce the confinement of the equivalent circular steel tube (Li, Zhao 2006). Denoting thicknessside radio $v=t / B$, the expression of the confinement reduction factor is $\zeta=66.4741 v^{2}+0.9919 v+0.41618$. Actually, the confining pressure to the in-filled concrete in the square tube is:

$$
\overline{p_{o}}=\zeta p_{o}
$$

As for the inner concrete, the confining pressure can be written as $\overline{p_{i}}=p_{i}+\overline{p_{o}^{\prime}}=p_{i}+\overline{p_{o}} \frac{D_{o}}{D_{i}}=p_{i}+\zeta p_{o} \frac{D_{o}}{D_{i}}$, so the actual compression strength of inner concrete can be expressed by:

$$
\overline{f_{c i}}=f_{c}+k_{c}\left(p_{i}+\zeta p_{o} \frac{D_{o}}{D_{i}}\right) .
$$

Meanwhile, there are effective and non-effective confining zones for the concrete inside the square steel tube. Concrete strength reduction factor is taken as $\gamma_{\mu}=$ $1.67 D_{o}^{-0.112}$ (Sakino et al. 2004) in order to homogenise these two effects. In the above equation, $D_{o}$ is the inside diameter of equivalent circular steel tube. Therefore, the actual compression strength of outer concrete can be expressed by:

$$
\overline{f_{c o}}=\gamma_{\mu} \sigma_{3}=\gamma_{\mu}\left(f_{c}+k_{c} \zeta p_{o}\right) .
$$

In Eqns (9) and (10), the unknown parameter is only the confining pressure, and it can be deduced by an analysis of steel tube subsequently. Under the state of ultimate balance, both outer and inner steel tubes are in threedimensional stress states including axial compression, radial compression and circumferential tension. In most of the CFST structures, diameter-thickness ratio or side length-thickness ratio of steel tubes is generally larger than 20 , and it can be regarded as a thin-walled cylinder. So the steel tube can be calculated under the plane stress state, i.e. radial compressive stress $\sigma_{r}=0$.

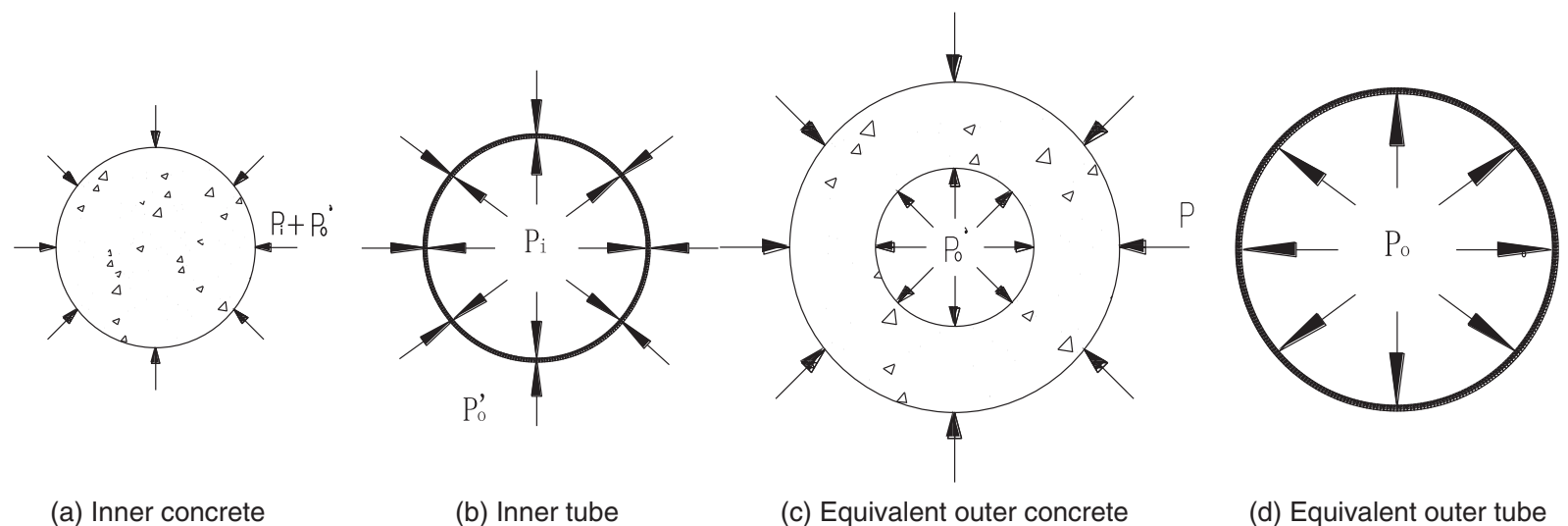

Fig. 4. Simplified model of stress of the composite column: (a) Inner concrete; (b) Inner tube; (c) Equivalent outer concrete; and (d) Equivalent outer tube 
According to UST, the stresses of steel tube in plate state are shown in Figure 5. When $b$ varies from 0 to 1 , a family of convex yield criteria suitable for any kind of materials are deduced. In particular, the UST becomes the Tresca criterion when $\alpha=1.0$ and $b=0$. The von Mises criterion can be linear approximated by the UST with $\alpha=1.0$ and $b=0.366$, and the Mohr-Coulomb criterion is obtained with $b=0$ (Yu 2004). No matter what $b$ takes for different strength theory, if circumferential tensile stress $\sigma_{\theta}$ arrives the yield strength, $\sigma_{z}$ axial compressive stress nearly becomes zero, and vice versa.

Actually, both the outer tube and the inner tube cannot reach this ideal state under the ultimate state of the column. The steel tube can still bear some vertical load under the ultimate state of the whole column and assume $\beta_{f}$ as the strength reduction factor of the steel tube, that is:

$$
\sigma_{3}=\sigma_{z}=\beta_{f} f_{y} .
$$

Therefore, stresses state of steel tubes can be explicated by $\sigma_{3}=\sigma_{z}=-\beta_{f} \sigma_{s}, \sigma_{2}=\sigma_{r}=0, \sigma_{1}=\sigma_{\theta}$. For $\left|\sigma_{3}\right|>\sigma_{1}$ and $\sigma_{2} \geq \frac{\sigma_{1}+\sigma_{3}}{1+\alpha}$, substitute them into the stress expression of UST (Eqn 3), and the following expression can be obtained:

$$
\frac{\sigma_{\theta}}{1+b}+\sigma_{z}=f_{y} .
$$

Meanwhile, the confining pressure on the concrete coming from circular steel tube can be written as:

$$
p=\frac{2 t}{D} \sigma_{\theta}
$$

The strain value of steel tube has been obtained at the ultimate state through the specimen's test. Then the circumferential tensile stress and vertical stress of steel

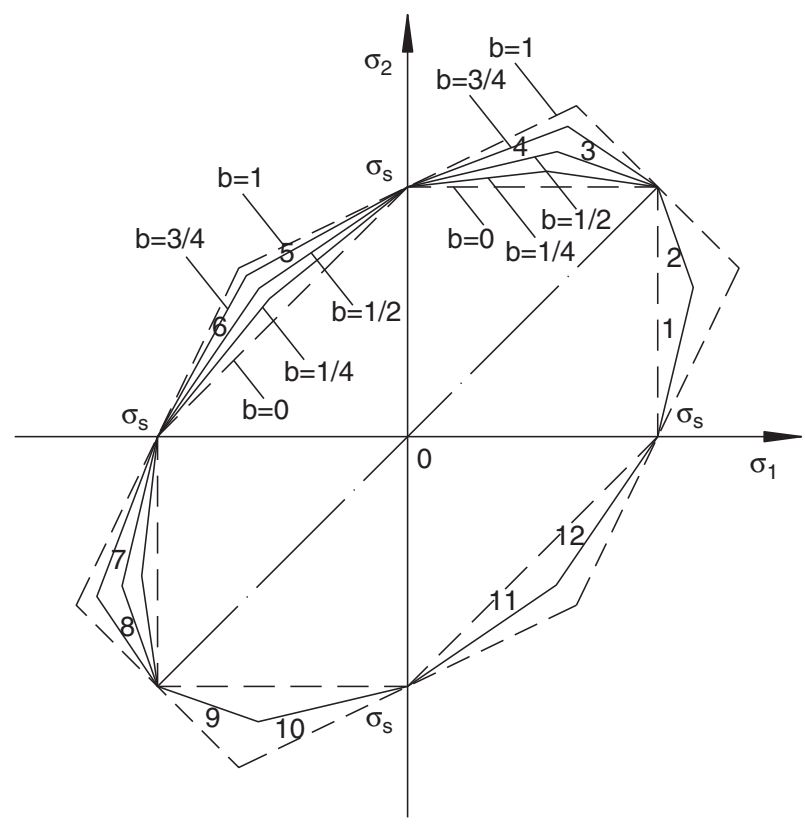

Fig. 5. Yield criterion in plane state tube can be derived by plastic theory and UST. Therefore, the following expression can be derived as follows:

$$
\beta_{f}=\frac{(u+2)(1+b)}{3(1+u)+b(u+2)},
$$

where $u=\varepsilon_{\mathrm{z}} / \varepsilon_{\theta} . \varepsilon_{\mathrm{z}}, \varepsilon_{\theta}$ are the vertical and circumferential strain of the steel tubes. The strain obtained from different gauging points in the experiment is shown in Table 2 when $b$ takes different value. For steel material, we can take the approximation of von Mises criterion as the final answer. In this paper, $\beta_{f}$ was taken as 0.65 in the calculation of bearing capacity of the steel tubes. Then synthesise Eqns (12) and (13), $\sigma_{\theta}$ and confining pressure $p$ can be deduced as follows:

$$
\sigma_{\theta}=0.4774 f_{y} ; p=0.9548 \frac{t}{D} f_{y} .
$$

Finally, substitute Eqns (9), (10) and (11) into Eqn (1), and the bearing capacity of the stub column can be calculated as follows:

$$
\begin{aligned}
N= & \beta_{f} f_{s i} A_{s i}+\beta_{f} f_{s o} A_{s o}+\left[f_{c}+k_{c}\left(p_{i}+\zeta p_{o} \frac{D_{o}}{D_{i}}\right)\right] A_{c i}+ \\
& \gamma_{\mu}\left(f_{c}+k_{c} \zeta p_{o}\right) A_{c o} .
\end{aligned}
$$

\section{Validation and parametric study}

\subsection{Comparison between calculated results and test results}

According to the above derivation, the axial compressive strength of CFSST column reinforced by a circular steel tube inside can be calculated by Eqn (16). Meanwhile, the main point of this method is to change the square tube to a circular one by the equal-area criterion, so the axial compressive strength of CFSST column can also be analysed by the above method. This paper presents the preliminary finding of the stub column tests of the CFSST column, and the compressive bearing capacity is calculated in comparison with the experimental results. The calculated results $(N)$ and experimental values $\left(N_{t}\right)$ are listed in Table 3 , including the data of this paper. It can be seen that the mean of $N / N_{t}$ is 1.022 and the coefficient of variation $(\mathrm{COV})$ is 0.061 . Meanwhile, the test results are also compared with the empirical models including the superposition method and the regression analysis. A review and comparison of the various expressions are provided later.

Superposition method does not take into consideration the concrete confinement. For example, Eurocode 4 (2004) is the most recent international design rules for composite columns design. The ultimate axial force of composite concrete-filled column is defined as follows: $N=f_{s} A_{s}+f_{c} A_{c}$. With some reduction factors, the ACI 318-08 Specification (ACI 2008) and Australian Standards also use the same superposition method for calculating the squash load. Herein, Eqn (17) has been deduced by Sakino et al. (2004), which is determined as follows:

$$
N_{\text {sup }}=f_{s} A_{s}+f_{c} A_{c} \gamma_{c},
$$

where $\gamma_{c}$ is a reduction factor introduced to take scale effect into consideration. 
Table 2. Calculation of vertical stress of steel tube under the ultimate state

\begin{tabular}{|c|c|c|c|c|c|c|c|c|c|c|c|c|}
\hline \multirow[b]{2}{*}{ Specimen } & \multirow[b]{2}{*}{$t$} & \multirow[b]{2}{*}{$D$} & \multirow[b]{2}{*}{$\sigma$} & \multirow[b]{2}{*}{$\varepsilon_{z}$} & \multirow[b]{2}{*}{$\varepsilon_{\theta}$} & \multirow[b]{2}{*}{$\mu$} & \multicolumn{2}{|c|}{$b=0$} & \multicolumn{2}{|c|}{$b=0.366$} & \multicolumn{2}{|c|}{$b=1$} \\
\hline & & & & & & & $\sigma_{z}$ & $\beta_{f}$ & $\sigma_{z}$ & $\beta_{f}$ & $\sigma_{z}$ & $\beta_{f}$ \\
\hline G1-2 & 1.4 & 58.5 & 352.5 & 2917 & 1232 & 0.43 & 200.1 & 0.57 & 226.2 & 0.64 & 255.3 & 0.72 \\
\hline G1-2 & 1.4 & 58.5 & 352.5 & 3375 & 1606 & 0.48 & 197.1 & 0.56 & 223.4 & 0.63 & 252.8 & 0.72 \\
\hline G1-2 & 1.4 & 58.5 & 352.5 & 3214 & 1477 & 0.46 & 198.0 & 0.56 & 224.2 & 0.64 & 253.6 & 0.72 \\
\hline G1-2 & 1.4 & 58.5 & 352.5 & 3767 & 1983 & 0.53 & 194.5 & 0.55 & 220.9 & 0.63 & 250.7 & 0.71 \\
\hline G1-3 & 0.9 & 74 & 680 & 2818 & 1218 & 0.43 & 384.9 & 0.57 & 435.3 & 0.64 & 491.6 & 0.72 \\
\hline G1-3 & 0.9 & 74 & 680 & 3382 & 1475 & 0.44 & 384.5 & 0.57 & 435.0 & 0.64 & 491.2 & 0.72 \\
\hline G1-3 & 0.9 & 74 & 680 & 3165 & 1172 & 0.37 & 392.1 & 0.58 & 442.0 & 0.65 & 497.4 & 0.73 \\
\hline G1-3 & 0.9 & 74 & 680 & 3655 & 1397 & 0.38 & 390.7 & 0.57 & 440.7 & 0.65 & 496.2 & 0.73 \\
\hline G1-4 & 0.9 & 83 & 597 & 3127 & 823 & 0.26 & 356.5 & 0.60 & 399.5 & 0.67 & 446.4 & 0.75 \\
\hline G1-4 & 0.9 & 83 & 597 & 3495 & 1020 & 0.29 & 353.0 & 0.59 & 396.3 & 0.67 & 443.7 & 0.74 \\
\hline G1-4 & 0.9 & 83 & 597 & 3910 & 1206 & 0.31 & 351.1 & 0.59 & 394.4 & 0.66 & 442.2 & 0.74 \\
\hline G1-4 & 0.9 & 83 & 597 & 3799 & 934 & 0.25 & 358.7 & 0.60 & 401.5 & 0.67 & 448.2 & 0.75 \\
\hline
\end{tabular}

Regression analysis was based on the test data considering steel ratio and confinement factor such as Unified Theory of CFST. It considered CFST as a unified composite material, and one equivalent confining coefficient $\xi_{s s c}$ is presented, which can be expressed as $\xi_{s s c}=\frac{\sum A_{s} f_{s}}{A_{c} f_{c}}$. And the bearing capacity of the composite column can be calculated by:

$$
N_{U T}=\left(1.212+m \xi_{s s c}+n \xi_{s s c}^{2}\right) f_{c}\left(A_{s}+A_{c}\right),
$$

where $m$ and $n$ reflect the contributions of steel tube and concrete, respectively. They can be calculated by $m=0.1759 f_{s s} / 235+0.974$ and $n=-0.1038 f_{c k} / 20+$ 0.0309 , respectively. For the CFSST column reinforced by circular steel tube inside, the $f_{s s}$ is the weighted strength average of the steel tubes, i.e. $f_{s s}=\frac{A_{s a} f_{s o}+A_{s i} f_{s i}}{A_{s o}+A_{s i}}$.

The ultimate axial loads of all the tests are compared with the predicted load from Eqns (17) and (18) and are shown in Table 3. These data show that superposition method gives a conservative prediction of underestimating the specimens, while Unified Theory of CFST appears to overestimate the specimens. Therefore, the comparison implies that the new method in this paper is yet an effective method to predict the resistance of the CFSST column reinforced by inner circular tube under axial compression.

\subsection{Parametric study of inner tube}

In order to further study the reinforcement function of inner circular steel tube inside CFSST, this paper has changed diameter-thickness radio of inner tube with no change of the steel ratio and steel strength of the composite column, so different axial bearing capacity $N$ can be obtained for every diameter-thickness radio of inner tube. While $N_{0}$ is the bearing capacity of steel tube and concrete without considering the reciprocity between steel tubes and concrete, i.e. $N_{0}=f_{s o} A_{s o}+f_{s i} A_{s i}+f_{c o} A_{c o}+f_{c i} A_{c i}$. The relationship between $N / N_{0}$ and the parameters of inner steel tube are shown in Figures 6 and 7. $N / N_{0}$ is the enhanced coefficient of bearing capacity which reflects the function of interaction process among outer, inner steel tubes and concrete. For every group, the steel ratio is the same, the value of $N_{0}$ is fixed, while the calculated value $N$ of the composite column is changed with the different parameters. Therefore, at the points where the value of $N / N_{0}$ is larger, stronger confining mechanism and more bearing capacity of the column will be validated.

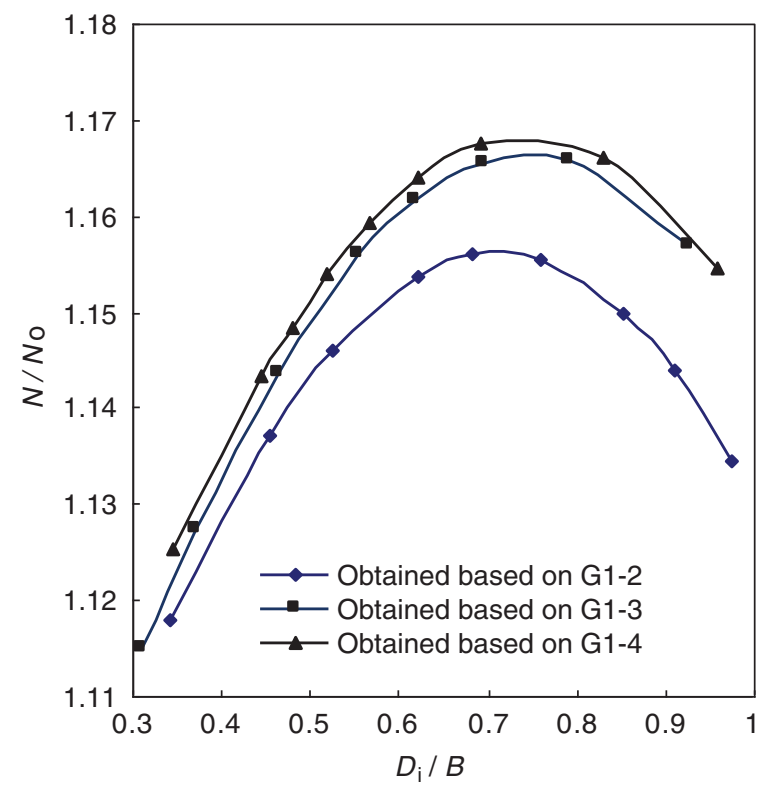

Fig. 6. Predicted axial load $\left(N / N_{0}\right)$ versus $D_{i} / B$ interaction curves 
Table 3. Comparison of calculated and experimental results

\begin{tabular}{|c|c|c|c|c|c|c|c|c|c|c|c|c|c|c|}
\hline Specimens & $\begin{array}{c}\text { Outer } \\
\text { tubular } \\
B \times t\left(\mathrm{~mm}^{2}\right)\end{array}$ & $\begin{array}{c}f_{\text {so }} \\
(\mathrm{MPa})\end{array}$ & $\begin{array}{c}\text { (Nominal) } \\
\text { Inner tubular } \\
\Phi D_{i} \times t_{i} \\
\left(\mathrm{~mm}^{2}\right)\end{array}$ & $\begin{array}{c}f_{c} \\
(\mathrm{MPa})\end{array}$ & $\begin{array}{c}N_{t} \\
(\mathrm{kN})\end{array}$ & $\begin{array}{c}N_{S U P} \\
(\mathrm{kN})\end{array}$ & $\begin{array}{l}N_{U T} \\
(\mathrm{kN})\end{array}$ & $\begin{array}{c}N \\
(\mathrm{kN})\end{array}$ & $\frac{N_{S U P}}{N_{\mathrm{t}}}$ & $\frac{N_{U T}}{N_{\mathrm{t}}}$ & $\frac{N}{N_{\mathrm{t}}}$ & $\begin{array}{c}N^{\prime} \\
(\mathrm{kN})\end{array}$ & $\begin{array}{l}\text { Increment } \\
\text { value }(\%)\end{array}$ & Literature \\
\hline CR4-C-8 & $215 \times 4.38$ & 262 & $\Phi 160 \times 2.0$ & 80.3 & 3837 & 3728.1 & 5362.0 & 4001.5 & 0.97 & 1.40 & 1.04 & 4810.6 & 25.4 & \\
\hline CR4-C-4-3 & $210 \times 4.50$ & 277 & $\Phi 160 \times 2.2$ & 39.1 & 2731 & 2389.8 & 3017.6 & 2621.8 & 0.88 & 1.11 & 0.96 & 3314.5 & 21.1 & Sakino \\
\hline CR8-D-8 & $265 \times 6.47$ & 835 & $\Phi 200 \times 2.6$ & 80.3 & 8990 & 9433.2 & 12280.8 & 8360.7 & 1.04 & 1.37 & 0.93 & 11138.6 & 23.9 & et al. (2004) \\
\hline CR8-C-9 & $180 \times 6.60$ & 824 & $\Phi 120 \times 1.5$ & 91.1 & 5873 & 5624.4 & 6770.1 & 5776.5 & 0.95 & 1.15 & 0.98 & 6987.9 & 19.0 & \\
\hline sczs 1-1-4 & $120 \times 3.84$ & 330 & $\Phi 80 \times 1.0$ & 33.0 & 1080 & 962.1 & 1125.3 & 1203.2 & 0.89 & 1.04 & 1.11 & 1351.0 & 25.1 & \multirow{5}{*}{$\begin{array}{c}\text { Han and } \\
\text { Tao (2001) }\end{array}$} \\
\hline sczs 1-1-2 & $120 \times 3.84$ & 330.1 & $\Phi 80 \times 1.0$ & 20.9 & 882 & 832.6 & 924.2 & 867.3 & 0.94 & 1.05 & 0.98 & 1094.8 & 24.1 & \\
\hline sczs 1-2-4 & $140 \times 3.84$ & 330.1 & $\Phi 100 \times 1.2$ & 36.6 & 1470 & 1254.5 & 1510.8 & 1541.0 & 0.85 & 1.03 & 1.05 & 1803.9 & 22.7 & \\
\hline sczs $2-1-4$ & $120 \times 5.86$ & 321.1 & $\Phi 80 \times 1.0$ & 35.2 & 1460 & 1253.9 & 1409.4 & 1375.4 & 0.86 & 0.97 & 0.94 & 1795.6 & 23.0 & \\
\hline sczs2-1-1 & $120 \times 5.86$ & 321.1 & $\Phi 80 \times 1.0$ & 20.1 & 1176 & 1103.5 & 1176.7 & 1353.3 & 0.93 & 1.00 & 1.15 & 1437.0 & 22.2 & \\
\hline CFRT40-3 & $200 \times 5$ & 277 & $\Phi 140 \times 1.7$ & 24.7 & 2016 & 1865.9 & 2189.4 & 2109.3 & 0.92 & 1.09 & 1.05 & 2776.4 & 37.7 & \multirow{4}{*}{$\begin{array}{c}\text { Lu et al. } \\
\text { (1999) }\end{array}$} \\
\hline CFRT40-5 & $200 \times 5$ & 277 & $\Phi 140 \times 1.7$ & 32.5 & 2468 & 2105.3 & 2920.9 & 2391.8 & 0.85 & 1.18 & 0.97 & 3179.4 & 28.8 & \\
\hline CFRT60-4 & $300 \times 5$ & 277 & $\Phi 210 \times 2.5$ & 28.3 & 4603 & 3685.0 & 5119.5 & 4674.7 & 0.80 & 1.11 & 1.02 & 5616.7 & 22.0 & \\
\hline CFRT60-5 & $300 \times 5$ & 277 & $\Phi 210 \times 2.5$ & 32.5 & 4381 & 3985.3 & 5018.3 & 4305.2 & 0.91 & 1.14 & 0.98 & 6065.3 & 38.4 & \\
\hline G1-1 & $120 \times 2.6$ & 407.5 & - & 23.6 & 896 & 772.9 & 892.3 & 922.3 & 0.86 & 0.99 & 1.03 & - & - & \multirow{4}{*}{$\begin{array}{c}\text { Data of this } \\
\text { paper }\end{array}$} \\
\hline G1-2 & $120 \times 2.6$ & 407.5 & $\Phi 58.5 \times 1.4$ & 23.6 & 980 & 858.5 & 1000.9 & 1031.0 & 0.87 & 1.02 & 1.05 & - & - & \\
\hline G1-3 & $120 \times 2.6$ & 407.5 & $\Phi 74.0 \times 0.9$ & 23.6 & 1040 & 911.0 & 1075.9 & 1111.9 & 0.88 & 1.03 & 1.07 & - & - & \\
\hline G1-4 & $120 \times 2.6$ & 407.5 & $\Phi 83.0 \times 0.9$ & 23.6 & 1080 & 908.3 & 1070.6 & 1113.0 & 0.84 & 0.99 & 1.03 & - & - & \\
\hline
\end{tabular}




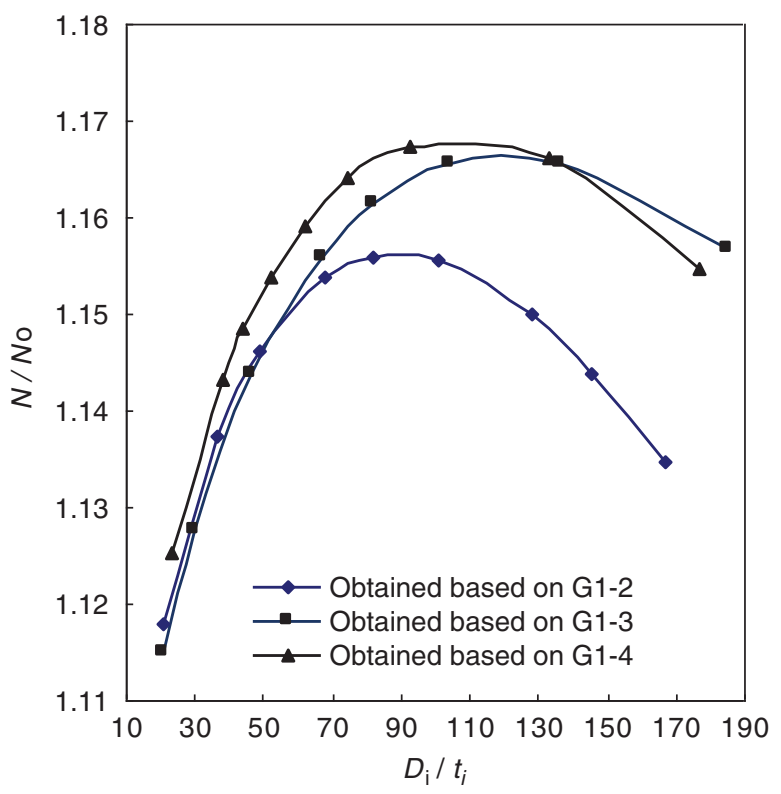

Fig. 7. Predicted axial load $\left(N / N_{0}\right)$ versus $D_{i} / t_{i}$ interaction curves

As can be seen from the curves, there are optimal parameters that can make the inner steel tube play best confinement to the composite column. The best $D_{i} / B$ to let the column have the maximum bearing capacity is in the neighbouring region of 0.75 . It demonstrates that the composite columns have the maximum capacities to resist axial compression when the $D_{i} / t_{i}$ ratios are between 80 and 100 .

\subsection{A simple model used in optimum design of inner tube}

More the confinement the concrete gets from tubes, the higher strength it is, we can analyse the deformation of concrete close to the ultimate state. There is a volume expansion of the whole concrete:

$$
\Delta V_{c}=\Delta V_{c o}+\Delta V_{c i} .
$$

The minimum value of $\Delta V_{c}$ can be calculated since $\Delta V_{c} \geq 2 \sqrt{\Delta V_{c o}} \cdot \sqrt{\Delta V_{c i}}$ :

$$
\begin{aligned}
\Delta V_{c \min }= & 2 \sqrt{\Delta V_{c o}} \cdot \sqrt{\Delta V_{c i}} \text { (only if } \sqrt{\Delta V_{c o}}= \\
& \left.\sqrt{\Delta V_{c i}}\right) .
\end{aligned}
$$

Hence, the composite column under axial compression has the highest load capacity when $\Delta V_{c o}=\Delta V_{c i}$.

A convenient and simple way to calculate the volume change of concrete is to assume $\Delta V_{c o}=g\left(V_{c o}\right)$ $V_{c o}$ and $\Delta V_{c i}=g\left(V_{c i}\right) V_{c i}$, where $g(\cdot)$ is a function of the concrete volume (Yuan et al. 2009). It can be seen that $g(\cdot)$ performs like an operator which is dependent on concrete volume. Therefore, according to Eqn (20), one obtains:

$$
g\left(V_{c o}\right)\left(B^{2}-\frac{\pi D_{i}^{2}}{4}\right)=g\left(V_{c i}\right) \frac{\pi D_{i}^{2}}{4}
$$

Eqn (21) can be rewritten as Eqn (22):

$$
\frac{D_{i}}{B}=\sqrt{\frac{2}{\pi\left[1+g\left(V_{c i}\right) / g\left(V_{c o}\right)\right]}} .
$$

It must be mentioned that different forms for function $g(\cdot)$ may be defined. Assuming $g(\cdot)$ is constant to define the simplest form, i.e. $g\left(V_{c i}\right)=g\left(V_{c o}\right)$, it can be obtained that $\frac{D_{i}}{B}=0.798$. Therefore, the best $D_{i} / B$ is very close to the result given in Figure 6.

\subsection{Contribution of inner tube}

In order to study the contribution of inner circular tube for the whole axial bearing capacity, the optimal circular steel tubes with the same strength of the square tubes were supposed inside the CFSST columns according to previous research results. As can be shown in Table 3, the comparison of the compressive bearing capacity was conducted between CFSST columns $\left(N_{t}\right)$ and those reinforced by nominal inner tubes $\left(N^{\prime}\right)$, and the increment value equals to $\left(N^{\prime}-N_{t}\right) / N_{t} \times 100 \%$. It can be seen that the calculated results have improved about $20 \%$ than the original results of the pure CFSST columns. Therefore, it can be found that with the same cross section, the bearing capacity of CFSST columns reinforced by inner circular steel tubes is a lot higher than the pure CFSST columns, and the contribution of inner circular tube inside the CFSST column is very significant.

\section{Conclusions}

The following conclusions are reached based on the experimental and analytical investigation reported in this paper.

The compressive bearing capacity and mechanic behaviour of the composite column were obtained by the tests. The typical failure mode of the composite column was local failure mechanism as same as the pure CFSST column caused by the expansion of the concrete under axial compression.

Through an elastoplastic limit analysis based on UST, an analytical formula, capable of predicting the axial bearing capacity of the CFSST columns reinforced by inner circular steel tubes subjected to axial compression, has been developed. Compared with the superposition method and the regression analysis, this model was verified by experimental results and was extended to predict the optimal design of the inner tube, namely, $D_{i} / t_{i}$ and $D_{i} / B$. Considering the confinement of both outer and inner steel tubes acting on the concrete to limit its volume expansion, another simplified model was also derived to predict the optimal diameter of inner circular steel tubes. With the optimal circular steel tubes inside the CFSST column, it is demonstrated that the bearing capacity of the composite column improves about $20 \%$ than pure CFSST columns with the same cross-section area. So it is very applicable to use inner circular tube to strengthen the CFSST column, and the use of composite columns can result in significant savings in column size, which 
ultimately can lead to bring the latent potentialities of material and thus realise greatly economic saves and higher bearing capacity.

\section{Acknowledgements}

The authors would like to acknowledge the support provided by the Chinese National Science Foundation (Grant No. 51008027) and the Special Fund for Basic Scientific Research of Central Colleges, Chang'an University (Grant No.CHD2011ZD009). Meanwhile, the financial support from North China University of Technology is also appreciated.

\section{References}

American Concrete Institute (ACI). 2008. Building code requirements for structural concrete and commentary. Farmington Hills, MI

EN 1994-1-1. 2004. Eurocode 4: design of composite steel and concrete structures. Part 1.1: general rules and rules for buildings. European Committee for Standardization.

Han, L.-H.; Tao, Z. 2001. Study on behavior of concrete-filled square steel tubes under axial load, China Civil Engineering Journal 34(2): 17-25. (in Chinese). http://dx.doi.org/10.1016/S0263-8231(03)00029-6

Han, L.-H.; Yang, Y.-F. 2003. Analysis of thin-walled steel RHS columns filled with concrete under long-term sustained loads, Thin-Walled Structures 41(9): 849-870.

Jiang, H.; Chu, L. C.; Zuo, J. 2008. Theoretical analysis and experimental study on normal cross-section load-carrying capacity for concrete-filled double steel tubular short columns subjected to axial compression load, Journal of Building Structures 29(4): 29-38. (in Chinese).

Li, X. W.; Zhao, J. H. 2006. Mechanics behavior of axial loaded short columns with concrete-filled square steel tube, Chinese Journal of Highway and Transport 19(4): 77-81. (in Chinese).

Lu, X. L.; Yu, Y.; Chen, Y. Y. 1999. Axial properties of concretefilled rectangular tubular column 1: test, Building Structures 29(10): 41-43 (in Chinese).

Ou, Z. J.; Chen, B. C.; Hsieh, K. H.; Halling, M. W.; Barr, P. J. 2011. Experimental and analytical investigation of concrete filled steel tubular columns, Journal of Structural
Engineering ASCE 137(6): 635-645.

http://dx.doi.org/10.1061/(ASCE)ST.1943-541X.0000320

Pei, W. J. 2005. Analysis on behavior of composite concretefilled steel tubes: Master Thesis. Chang'an University, Xi' an, China.

Richart, F. E.; Brandtzaeg, A.; Brown, R. L. 1928. A study of the failure of concrete under combined compressive stresses. Bulletin No. 185. Urbana, IL: University of Illinois, Engineering Experimental Station. 104 p.

Roeder, C. W.; Lehman, D. E.; Bishop, E. 2010. Strength and stiffness of circular concrete-filled tubes, Journal of Structural Engineering ASCE 136(12): 1545-1553. http://dx.doi.org/10.1061/(ASCE)ST.1943-541X.0000263

Roeder, C. W.; Lehman, D. E.; Thody, R. 2009. Composite action in CFT components and connections, Engineering Journal AISC 47(4): 229-242.

Sakino, K.; Nakahara, H.; Morino, S.; Nishiyama, I. 2004. Behavior of centrally loaded concrete-filled steel-tube short columns, Journal of Structural Engineering ASCE 130(2): 180-188.

http://dx.doi.org/10.1061/(ASCE)0733-9445(2004)130: $2(180)$

Tan, K. H.; Zhang, Y. F. 2010. Compressive stiffness and strength of concrete filled double skin (CHS inner \& CHS outer) tubes, Journal of Mechanics and Materials in Design 6(3): 283-291.

http://dx.doi.org/10.1007/s10999-010-9138-y

Varma, A. H.; Ricles, J. M.; Sause, R.; Lu, L.-W. 2004. Seismic behavior and design of high-strength square concrete-filled steel tube beam columns, Journal of Structural Engineering ASCE 130(Special Issue: Composite and hybrid structures): 169-179.

Yu, M. H. 2004. Unified strength theory and its application. Heidelberg: Springer, Berlin. 421 p. http://dx.doi.org/10.1007/978-3-642-18943-2

Yuan, W. F.; Tan, K. H.; Zhang, Y. F. 2009. A simple model used in optimum design of concrete-filled twin steel tubular column, in Proc. of the 6th International Conference on Advances in Steel Structures, 2009, Hong Kong, 514-519.

Zhong, S. T. 2000. The comparison of the composite rigidities with the conversion rigidities for CFST members, in Proc. of the 6th ASCCS Conference, 2000, Los Angeles, $22-24$.

Yufen ZHANG. An Associate Professor of College of Architecture and Civil Engineering, North China University of Technology, China. She is also a postdoctoral researcher at the Department of Civil Engineering, Tsinghua University, China. Her research interests include the analysis of the connection between CFST column and frame beam, particularly the behaviour of CFST column.

Junhai ZHAO. Professor of School of Civil Engineering, Chang'an University, China. He is a doctor instructor with nearly 50 graduate students in graduate school. His research interests include strength theory, solid mechanics, Chinese ancient wood structure and steel-concrete composite structure.

Weifeng YUAN. Senior research fellow in the School of Civil and Environmental Engineering, Nanyang Technology University, Singapore. His research interests include computational solid mechanics, structural fire safety and evacuation modelling. 